\title{
Dialoging About English Learners: Preparing Teachers Through Culturally Relevant Literature Circles.
}

Amy J. Heineke

Loyola University Chicago, aheineke@luc.edu

Follow this and additional works at: https://ecommons.luc.edu/education_facpubs

Part of the Education Commons

\section{Author Manuscript}

This is a pre-publication author manuscript of the final, published article.

\section{Recommended Citation}

Heineke, Amy J.. Dialoging About English Learners: Preparing Teachers Through Culturally Relevant Literature Circles.. Action in Teacher Education, 36, 2: , 2014. Retrieved from Loyola eCommons, Education: School of Education Faculty Publications and Other Works, http://dx.doi.org/10.1080/

01626620.2014 .898600

This Article is brought to you for free and open access by the Faculty Publications and Other Works by Department at Loyola eCommons. It has been accepted for inclusion in Education: School of Education Faculty Publications and Other Works by an authorized administrator of Loyola eCommons. For more information, please contact ecommons@luc.edu.

\section{(c) $(1) \ominus$}

This work is licensed under a Creative Commons Attribution-Noncommercial-No Derivative Works 3.0 License. (c) Association of Teacher Educators, 2014. 
Running Head: LITERATURE CIRCLES

Dialoging about English Learners: Preparing Teachers through Culturally Relevant Literature Circles

\author{
Non-Thematic Topic \\ Submission Date: June 10, 2013 \\ Amy J. Heineke, Ph.D. \\ Assistant Professor of Education \\ Bilingual/Bicultural Education \\ School of Education \\ Loyola University Chicago \\ 820 North Michigan Avenue \\ Lewis Towers, $11^{\text {th }}$ Floor \\ Chicago, Illinois 60611 \\ Office Phone: (312) 915-7027 \\ Office Fax: (312) 915-6660 \\ Home Phone: (773) 930-4447 \\ aheineke@luc.edu
}

Amy Heineke focuses her research on teacher preparation for English learners. Her pursuits in teacher education are guided by her prior work as an elementary teacher in Phoenix, Arizona.

Author's Note: The author thanks the undergraduate and graduate students who agreed to participate in the study, as well as the graduate assistants in the School of Education at Loyola University Chicago who dedicated extensive time to complete the literature discussion transcriptions. The author can be contacted via email at: aheineke@luc.edu. 


\begin{abstract}
In this paper, I describe how culturally relevant children's literature allowed teachers and teacher candidates to explore the lived realities of diverse students. Through my qualitative investigation of 23 literature discussions of undergraduate and graduate students across five academic semesters, I found that texts written by culturally and linguistically diverse authors gave participants new ways to articulate ideas and beliefs about English learners. I discovered specific factors that opened or closed opportunities for dialog and learning in literature circles, including implementation of reader response strategies and various participant groupings. Results hold implications for preparing and supporting teachers to recognize and value the rich diversity of English learners in classrooms.
\end{abstract}


Dialoging about English Learners: Preparing Teachers through Culturally Relevant Literature Circles As the United States (U.S.) school-age population becomes more culturally and linguistically diverse, so do the disproportioned demographics between teachers and students in educational settings (Gándara \& Hopkins, 2010). Eleven million students in the U.S., or 20 percent of national school enrollment, speak a language other than English at home; about one-half of these students do not speak English well enough to be considered fluent (U.S. Department of Education, USDOE, 2010). Educators must be prepared to support the social, emotional, cultural, linguistic, and academic development of English learners (ELs) in classrooms and schools (Heineke, Coleman, Ferrell, \& Kersemeier, 2012; Wrigley, 2000). Nevertheless, under-prepared teachers educate the large majority of ELs in the U.S. (Cohen \& Clewell, 2007). In teacher education programs, current and future educators need opportunities to go beyond general instructional strategies for teaching ELs to explore students' diverse and unique realities, funds of knowledge, and ways of thinking and being (González, Moll, \& Amanti, 2005).

Recognizing the limitations of textbooks to account for this rich diversity among the millions of students usurped under the homogenous label of EL (Gutiérrez \& Orellana, 2006), I investigate the dialog of teachers and teacher candidates engaged in literature circles with culturally relevant texts that portray the individually nuances lives of linguistically diverse children and families. Culturally relevant literature refers to texts written by and about people of marginalized cultures, or people whose stories and experiences have been historically underrepresented in the literary canon (Bishop, 1994). Literature circles allow for reading, exploring, and discussing real books to collaboratively take and make meaning from stories (Daniels, 2002). By using picture books with undergraduate and graduate students enrolled in EL teacher preparation programs, culturally relevant texts serve as windows, mirrors, and sliding glass doors into the lives of diverse children and 
families; windows provide glimpses into the lives of others, mirrors facilitate connections between readers and characters, and sliding glass doors invite participation in the story (Bishop, 1990).

In response to the growth in ELs in U.S. classrooms and schools, scholars recognize the importance of teachers having language-specific knowledge and skills (Valdés, Bunch, Snow, Lee, \& Matos, 2005) and advocate for linguistically responsive teacher education (Lucas, Villegas, \& Freedson-González, 2008); however, the literature on teacher education for ELs remains largely conceptual. When spanning out to consider empirical studies of teacher preparation for culturally diverse students, research finds the efficacy of culturally relevant texts to build cultural awareness and sensitivity (Labbo, 2007; Wood et al., 2001) and mediate conversations around issues of culture through book clubs, typically utilizing chapter books written for adolescents (Florio-Ruane, 2001; Martínez-Roldán \& Heineke, 2011; Rodgers \& Mosely, 2008). In this empirical study on teacher preparation for ELs, I seek to close multiple gaps in the literature by investigating culturally relevant literature circles with picture books, typically a pedagogical approach reserved to support children's reading and meaning making (Barone \& Barone, 2012; Latendresse, 2004; McElvain, 2010), with characters and plots that merge the social, emotional, cultural, linguistic, and academic dimensions of EL student development (Heineke et al., 2012; Herrera, 2010; Wrigley, 2000).

In this paper, I explore my findings on teachers' and candidates' participation, collaboration, and learning in culturally relevant literature circles in teacher education coursework, specifically investigating factors that open and close opportunities for learning. Overall, results indicate that the use of culturally relevant picture books and literature discussion strategies engage current and future teachers in dialog around the individual stories and experiences of ELs in relation to classroom practice. To begin, I review extant literature on collaborative teacher preparation for cultural and linguistic diversity and describe the theoretical and conceptual framework related to sociocultural teacher learning. Next, I outline the qualitative methods to investigate the 23 literature discussions 
across five academic semesters at an urban Midwest university. I then share findings related to culturally relevant literature circles, as well as the logistics to support teacher learning. Finally, I close with discussion for teacher preparation for cultural and linguistic diversity.

\section{Collaborative Teacher Learning for Cultural and Linguistic Diversity}

With the growing population of ELs in classrooms across the U.S. (USDOE, 2010), scholars propose ideas to adequately prepare teachers for this vulnerable subgroup (Gándara \& MaxwellJolly, 2006), asserting that teachers must understand big ideas about language and apply linguistic knowledge to the teaching and learning of various disciplines (Valdés et al., 2005). Big ideas about language include knowledge of linguistics (Ann \& Peng, 2005; Valdés et al., 2005), linguistic diversity (Valdés et al., 2005), social justice issues (Bartolomé \& Balderrama, 2001), linguistically responsive practices (Lucas et al., 2008), and EL instructional strategies (Commins \& Miramontes, 2006). Although recommendations for teacher preparation may be grounded in theory and research on ELs, empirical studies are lacking to determine whether teacher learning for linguistically diverse students occurs based on given suggestions. When taking a wider lens on teacher preparation for culturally diverse students, the literature converges on the efficacy of two bodies of literature central to this study: (a) teacher learning communities and (b) the integration of children's literature.

Recognizing the need for teachers to collaboratively make meaning of knowledge and practice (Cochran-Smith \& Lytle, 1998), extant research on in-service teacher learning emphasizes the oft used professional development construct and context of teacher learning communities (McLaughlin \& Talbert, 2006). Scholars share and promote various small-group contexts to promote teacher learning, including communities of practice (Little, 2002) and study groups (Birchak et al., 1998), as well as book clubs (Florio-Ruane, 2001; Rodgers \& Mosely, 2008) and literature circles mediated by chapter books (Martínez-Roldán \& Heineke, 2011; Monroe-Baillargeon \& Shema, 2010). Focused specifically on teacher learning about culturally diverse students, studies demonstrate 
the efficacy of book clubs with adolescent literature (Florio-Ruane, 2001; Rodgers \& Mosely, 2008). When honing in on small-group discussions on linguistic diversity and ELs, the construct of the teacher study group has been implemented and studied in school-based settings with in-service teachers (Clair, 1998; Musanti \& Pence, 2010). To my knowledge, prior research has not explored the pedagogical construct of literature circles using culturally relevant picture books to target EL teacher preparation with pre-service or in-service educators.

Whereas learning communities are typically the foci of research with in-service teachers, scholars investigate the exposure to and integration of literature written for children and adolescents into pre-service teacher preparation. Approached through methods courses specifically focused on children's literature for elementary candidates (Gregor \& Green, 2011; Lohfink \& Curtis, 2011) or adolescent literature for middle school and secondary candidates (Wood, Roser, \& Martínez, 2001), extant research has demonstrated the efficacy of multicultural literature to allow teacher candidates opportunities to (a) embrace positive cultural sensitivity (Labbo, 2007), (b) foster cultural expression through text-to-self connections (Wood et al., 2001), (c) develop awareness of and select culturally relevant materials (Lohfink \& Curtis, 2011), (d) identify with diverse students (Nathenson-Mejia \& Escamilla, 2003), and (e) explore specific issues impacting diverse children, such as immigration (Gregor \& Green, 2011). Whereas past studies have demonstrated the value of multicultural texts for individual teacher development around culture, this study emphasizes the collaborative lens of interaction within the pedagogical structure of literature circles, specifically focused on teachers' and candidates' learning for ELs and linguistically diverse students, families, and communities.

Despite the focus on learning communities for in-service teachers and children's literature for pre-service teachers, the efficacy and value of collaborative literature discussions to support learning has primarily been conducted with children (Martínez-Roldán \& Malavé, 2004; McElvain, 2010; Medina \& Martínez-Roldán, 2011) and adolescents (Barone \& Barone, 2012; Latendresse, 
2004; Peterson \& Belizaire, 2006). Supporting facets central to students' reading, literature circles have been shown to boost reading engagement (McElvain, 2010), comprehension (Latendresse, 2004), background knowledge, and critical literacy (Barone \& Barone, 2012). Within the general pedagogical approach of literature circles, research has demonstrated that unstructured small-group settings deter from deep dialog (Thein, Guise, \& Sloan, 2011) and specific strategies support discussion, such as the use of roles (Barone \& Barone, 2012; Peterson \& Belizaire, 2006). Scholars have found literature circles to be effective (a) in supporting language development of ELs (Fredericks, 2012; McElvain, 2010; Shelton-Strong, 2012) and (b) through use of culturally relevant texts with children (Martínez-Roldán \& Malavé, 2004; Medina \& Martínez-Roldán, 2011). Building on these studies with children and adolescents, this study focuses on teacher preparation for ELs in literature circles mediated by culturally relevant texts.

Seeking to fill the aforementioned gaps in the literature, this study investigates how culturally relevant picture books mediate teachers' and candidates' learning in literature circles. In this empirical study centered on teacher learning for ELs, I extend the small-group approach to cultural diversity utilized with in-service teachers in school settings to include exploration of candidates' learning in culturally relevant literature circles about the social, emotional, cultural, linguistic, and academic abilities and needs of ELs in the university setting (Heineke et al., 2012; Wrigley, 2000). Extending an effective pedagogical approach for children and adolescents (Barone \& Barone, 2012; Latendresse, 2004; Martínez-Roldán \& Malavé, 2004; Medina \& Martínez-Roldán, 2011; Peterson \& Belizaire, 2006), I investigate the use of literature circles with teachers and teacher candidates. Through the theoretical framework of sociocultural teacher learning and the conceptual framework of communities of practice, I explore literature discussions related to learning about ELs.

\section{Teacher Learning in Communities of Practice}


The sociocultural paradigm recognizes that individuals co-construct knowledge by interacting with one another in social settings (Rogoff, 2003; Vygotsky, 1978). This collaborative construction of knowledge occurs through the mediation of cultural artifacts or tools (Rogoff, 2003), specifically (a) language due to its centrality to the sociocultural conception of learning (Gee, 2005; Vygotsky, 1978), and (b) literature, considered to be a psychological and cultural artifact that mediates cognitive change and the human experience (Kozulin, 1998). Incorporating both language and literature to mediate learning through social interaction, literature circles bring individuals together to participate in communities of learners (Rogoff, 1994), communities of practice (Wenger, 1998), or learning communities (McLaughlin \& Talbert, 2006) where educators inquire into and make meaning of practice in classroom and schools (Cochran-Smith \& Lytle, 1998; Grossman, Wineburg, \& Woolworth, 2001). Within the sociocultural theoretical framework, teacher learning is understood as situated in social practice (Wenger, 1998) - occurring when participants collaborate in communities through shared repertoires and change participation over time (Rogoff, 1994), such as teachers' changing talk about ELs through participation in teachers' communities of practice.

Grounded in the sociocultural paradigm, Little’s conceptual framework (2002) supports investigation of the significance and efficacy of the community construct to teacher learning and development. Aiming to locate learning in teachers' communities of practice, the conceptual scheme aims to "unpack the relations among teacher community, teacher development, and the improvement of practice" (p. 934) through analysis of representations of practice, orientations to practice, and norms of interaction. First, recognizing a shortcoming of the general community of practice literature, specifically the ambiguity around how community practice becomes known and shared (Fuller, 2007), representations of practice expose how teachers interact with one another within the collaborative context to exchange and make meaning of particular aspects of teaching and learning. Second, since learning community scholars recognize that not all professional communities 
contribute to improved teaching and learning (Cochran-Smith \& Lytle, 1998; Grossman et al., 2001; McLaughlin \& Talbert, 2006), orientations to practice focus on the specific instances in collaborative dialog that open up or close down considerations of practice and opportunities for learning. Third and finally, norms of interaction provide insight into the "structures and processes of participation" (Little, 2002, p. 936) that support inquiry into practice, which elucidate the dynamic and complex nature of individual learners within wider social memberships (Engeström, 2007).

Using the sociocultural theoretical framework to understand the situated and collaborative nature of teacher learning (Rogoff, 2003; Vygotsky, 1978) and the conceptual framework to locate teacher learning in communities of practice (Little, 2002), I explore the following research questions in this study: (a) How does participation in culturally relevant literature circles support teachers' and teacher candidates' dialog about ELs? (b) What factors open or close opportunities for learning in culturally relevant literature circles with teachers and teacher candidates? In the next section, I share details of the qualitative study (Erickson, 1986), including context and participants, data collection, data analysis, and validity and researcher role, to investigate these research questions.

\section{Methods}

\section{Context and Participants}

I conducted culturally relevant literature circles in undergraduate and graduate teacher education courses at Loyola University Chicago, a private, Midwest university in the diverse, urban metropolis of Chicago, Illinois. Situated in a state with more than 1 in 5 residents over the age five speaking a non-English language in the home (Shin \& Kominski, 2010) and 136 non-English languages represented by students enrolled in schools (Ruiz \& Koch, 2011), 29\% of the state's ELs attend urban schools and 59\% attend nearby suburban schools (Ruiz \& Koch, 2011). To prepare educators for the diverse realities of urban and suburban classrooms, I taught EL-specific courses to pre-service teacher candidates and in-service teachers who opted into ESL and bilingual 
endorsement courses. When appropriate for class topics and learning objectives, I engaged undergraduate and graduate students in literature discussions with culturally relevant picture books in EL foundations, assessment, and literature courses. Participants read culturally relevant texts prior to class and engaged in literature discussions with peers, typically using pre-selected reader response strategies to mediate collaborative dialog (Short, 1997).

[Insert Table 1 around here.]

Collected across five semesters, 23 in-class literature circles provided a participant sample of teachers and candidates enrolled in 8 course sections. The 4 sections of undergraduate classes preservice sophomores, juniors, and seniors enrolled in ESL endorsement coursework. Undergraduate participants in literature circles were 88\% female and 12\% male from 65\% White, 29\% Latino, and $6 \%$ Asian backgrounds. The 4 sections graduate classes consisted of $36 \%$ of pre-service participants seeking ESL endorsements in addition to teaching certification, $45 \%$ of in-service teachers returning to complete university coursework required for the state ESL endorsement, and 18\% in other graduate programs taking ESL-related courses as electives. Graduate participants were $82 \%$ female and 18\% male from 58\% White, 21\% Latino, 15\% Asian, and 6\% Black backgrounds. ${ }^{1}$ In-service teacher participants, with placements ranging from early childhood to high school, had one to multiple ELs in their urban and suburban classrooms.

[Insert Table 2 around here.]

\section{Data Collection}

To capture the social interaction of discussions mediated by culturally relevant texts, I employed qualitative methods (Erickson, 1986) to collect and analyze data. I utilized a digital voice recorder to audio record the collaborative dialog and then transferred and cataloged the audio files, making note of key attributes of the discussion, including mediating text, participant pseudonyms,

\footnotetext{
${ }^{1}$ Due to the large sample size represented in the data presented in this paper $(\mathrm{N}=99)$, the diversity among literature circle participants is presented using standard labels for classification.
} 
participant details (e.g., class, academic major), and discussion details (e.g., selected or assigned text, strategy or procedure used). With the help of graduate assistants, I transcribed all audio files into Word documents to upload to Nudist-Vivo qualitative software for data analysis. In addition to audio and transcription files from small-group discussions, data also included mediating texts (e.g., picture book), resulting reader response artifacts (e.g., poster from Graffiti Board), participant reflections, and my research memos and notes following class sessions with literature circles.

\section{Data Analysis}

Since the study design highlighted the role of language (Vygotsky, 1978) and literature (Kozulin, 1998) in the mediation of knowledge, I utilized discourse analysis (Gee, 2005) of data from

culturally relevant literature circles. I immersed myself in transcribed and audio-recorded data to first recognize patterns of words and phrases and then discern themes related to research questions. Using theoretical orientation to approach the iterative analysis (Erickson, 1986), specifically Little's conceptual framework (2002) to locate learning in teachers' communities of practice, I incorporated a three-facet scheme to code the linguistic details, analyze teachers' discourse, and interpret emergent themes. Through analysis of representations of practice, I examined how teachers portrayed practice with and perceptions of ELs in social interaction, specifically utilizing the codes of windows, mirrors, and sliding glass doors (Bishop, 1990). With the lens of orientation to practice, I analyzed data for instances that opened or closed opportunities for learning in the small-group literature discussions, such as scaffolds and statements that supported deep-level exploration of ideas rather than surface-level observation of texts. I also scrutinized the norms of interaction within the literature circles, which looked at various factors that mediated teachers' collaborative discourse.

\section{[Insert Table 3 around here.]}

\section{Validity and Researcher Role}

Wearing the hats of both course instructor and researcher, I consistently negotiated the dual 
role inherent in the study design. Prior to in-class literature circles, I invited voluntary participation, using a recruitment script that outlined the safeguards, including that participation and consent was not tied to course grades and the guaranteed time delay on all data review and analysis (i.e., after the end of semester). During literature circles, I typically moved around the room without interjecting, so as to not impact the trajectory or content of the dialog. After literature circles, I maintained a researcher journal to write memos related to the data collection (e.g., mediating texts, groupings) and my role during the session (e.g., preliminary introduction of texts, asked questions to provoke dialog in group X). Throughout data collection and analysis, I implemented strategies to reduce bias and enhance validity of findings, including the prolonged and persistent field work across five semesters, collection of multiple data sources (e.g., reflections and artifacts to triangulate findings), and the use of graduate assistants to support both data collection (i.e., transcription) and analysis (e.g., emergent codes). By negotiating my dual role and employing strategies to enhance validity, the study yielded results significant to understanding collaborative teacher learning for ELs.

\section{Results}

In this section, I share results on teachers' culturally relevant literature circles. I organize the results into two sub-sections to respond to the research questions. In the first sub-section, I share findings related to the first question: How does participation in culturally relevant literature circles impact dialog about ELs? In the second sub-section, I outline themes related to the second question: What factors open or close opportunities for learning in culturally relevant literature circles? I then discuss recommendations related to teacher preparation for ELs and diverse students.

\section{Teacher Learning in Literature Circles}

I found that teachers and teacher candidates learned about ELs through participation in culturally relevant literature circles. Through use of texts to provide common frames to engage in discussions about children and families, literature mediated dialog by providing windows, mirrors, and 
sliding glass doors (Bishop, 1990) to represent the lives of diverse students. In this sub-section, I share findings on teachers' and candidates' representations of practice (Little, 2002), when mediating texts served as (a) windows to learn about realities of ELs, (b) mirrors to connect with past experiences with teaching and learning, and (c) sliding glass doors to explore implications for teaching practice. In each sub-section, I describe and provide examples of how participants utilized texts as tools to coconstruct knowledge.

Windows to learn about lived realities of individual English learners. The use of culturally relevant texts provided participants with windows into the lived realities of ELs (Bishop, 1990), as stories provided nuanced accounts of individual students inside and outside of school. Typically occurring with teachers and candidates from mainstream American backgrounds, texts allowed participants to dialog about the social, emotional, cultural, linguistic, and academic facets of ELs in classrooms.

In spring 2012, three teacher candidates at the graduate-level engaged in a literature circle with Shota and the Star Quilt (Bateson-Hill, 2001), the story of a Native American girl and her family who faced numerous difficulties when forced from their home. Jana utilizes the text as a window into the life of Esther, a young Lakota character portrayed in the Native American children's book.

Arturo: I was surprised that there is no beating around the bush [in the text]. There was one line where the dad was like, "Yet again we're getting kicked out of our home. Some things never change!”

Jana: It's like dealing with adult problems, the kids are. You're not dumbing the things [realities] down for them or like keeping them away from it. The kids are in the [family] action and I think that is a common theme in a lot of the EL children's literature that I've read. It's because they're dealing with so much they're often acting as the translator for the 
parents at school and dealing with these difficult transitions from other countries, crossing the borders and all that. So I think it's really telling the things that are in here [in the text]. Arturo: Well, I think it's something that you have to address [as a teacher], especially if you have a classroom with certain [culturally diverse] factions of students and families...

Jovana: The mention of the family structure - Esther has the apartment all her life; mother, father, brothers and the grandmother shows extended family that a lot of students definitely have. I mean I was in one of those [families]. We had a lot of kids in one little place.

As reflected in the small-group discourse, Jana represented the challenges faced by many children by using third-person narrative (e.g., "they're dealing"), such as the social and emotional trauma of losing a house and the cultural and linguistic demands to serve as a translator for parents and families. Jovana, from a large Eastern European immigrant family, used first-person narrative (e.g., "I was," "we had"), demonstrating her association to the text as a mirror to connect individually with the protagonist and specific context of the story. In a class session focused on assessing ELs' funds of knowledge from families and communities, the text provided a common character and plot to discuss the assets and realities of one culturally and linguistically diverse child.

Mirrors to connect experiences with culture, language, and learning. When teachers and candidates forged personal connections to culturally relevant texts, they utilized literature as mirrors to see themselves in the story's narrative (Bishop, 1990). Typically occurring with participants from culturally and linguistically diverse backgrounds, mirror-based representations of practice included connections to topics posed in various texts, such as family traditions, circumstances of immigration, language learning, and school experiences.

In spring 2011, five teacher candidates read two picture books related to borders and immigration to mediate a literature discussion on immigrant students' funds of knowledge. Along with one male participant who grew up in Chicago and learned Spanish as a second language in high 
school, the group consisted of four females who self-identified as first- and second-generation immigrants from Poland, Guatemala, and Mexico and learned English early in school. In their collaborative dialog about My Diary from Here to There (Pérez, 2009) and Going Home (Bunting, 1998), participants used the texts as mirrors reflecting on background knowledge and experiences.

Ariadna: I can relate to both [texts]. My Diary from Here to There is like me coming from Poland to the states and a lot of the feelings that the girl was going through I felt the same way on my journey from Poland to here. And then for Going Home I am always really excited to go back home and visit my family and just like the parents in the book were really happy and felt safe and they were actually home, that's how I feel when I go back there [to Poland]. Natasha: Me and Selena were talking about which book was our favorite and it is hard to decide because the diary of coming here and how the girl rose over her journey but then Going Home, the feeling that the parents had when they went there [Mexico] and how the kids saw a different side of their parents that they haven't seen. It was heartwarming. Selena: It made me feel sad, Going Home. Yesenia: Oh yeah it made me cry, I actually cried like at the end when the kid discovers like why their parents left their home he kind of like understands like oh this is why they left. Ariadna: Because it's true, our parents come here to have better opportunities but like we don't realize that. And they work so hard for us to have a better life.

Selena: And then it will be after our opportunities so they came to work and it's not until after they achieve what they wanted, like a better life for their kids, that's when they're gonna be able to enjoy their life having that made me really sad because that is why my parents came here. My poor parents are breaking their backs working. 
Natasha: That reminds me of a [Polish] family I know that has five kids, the dad works all the time and he hasn't been to visit his country in like 10 years maybe or 11 because he just can't afford it and he wants to be there for the kids and it's just like that stinks.

Ariadna: My mom is going to Poland this year for the first time in 13 years after being here [in the U.S.] and working so hard. It breaks my heart to see her.

After using first-person narratives to make text-to-self connections, specifically focusing on their own parents (i.e., Selena, Yesenia, Ariadna) or those within their cultural communities (i.e., Natasha), participants continued to represent practice by using texts as mirrors. When discussing Amada's experiences in My Diary from Here to There, the two Latina teacher candidates, who both immigrated with their families at young ages, engaged in first-person accounts of citizenship, permanent residency, and green cards; the two second-generation Polish immigrant participants connected and elaborated on the maintenance of native language through heritage language classes and family gatherings. Connecting with the character in Going Home, all candidates reflected upon experiences returning to Poland, Guatemala, and Mexico as adult women more connected to the U.S. than their native countries. With culturally relevant texts that served as mirrors into their own experiences in immigrant families, participants used their families' sacrifices and challenges to represent the social, emotional, and linguistic demands placed on immigrant children.

Sliding glass doors to explore implications for future teaching practice. In addition to using texts as windows to peak into the lives of ELs from the outside, or mirrors to make meaning of personal experiences with teaching and learning, participants also used culturally relevant literature circles to open sliding glass doors (Bishop, 1990) to step into students' unique realities and think through implications in professional practice as classroom teachers.

In fall 2012, graduate students closed the semester with discussion mediated by self-selected poems written from the perspective of a young EL in My Name is Jorge on Both Sides of the River 
(Medina, 2001) using the Save the Last Word for Me reader response strategy (Short, 1997); one participant selected a poem to read aloud for others to respond with emergent thoughts.

Arturo: "Why am I dumb? In my country I was smart. All tens. Never even an eight. Now I'm here. They give me Cs or Ds or Fs. Like fives or fours or ones. I feel like I'm turning into Kiko from my old class. Kiko's dumb in any country. Well, I'm still smart in math. Maybe dumb in reading, but math, all tens. I mean, As."

Jovana: It just shows that more kids get to do a little bit better in the math because it's numbers, he [Jorge] doesn't have to rely on the words as much. And then, even those [students] coming in who don't know our [American] grading system might be thrown off a little bit at first, but that's easy to explain quickly. But again, the affective filter, they [EL students] feel dumb, they're not going to try as hard or be more scared to try.

Diana: I like the contrasting of dumb versus smart, the use of " 10 s" versus the letters. Being smart in math versus being dumb in reading, and then how he throws in there, "Kiko is dumb in any country." (laughter) But it's interesting, too, because I can see how a kid could feel that way. They come to this country thinking, "Yeah! I was the smartest one in my class!" And in many cases, some kids are, like the level at which they were learning in their own country can be much higher than here in the U.S., and yet, they're [perceived to be] the "dumb ones." I found that to be kind of sad.

Norma: I was going to also add on to that, the expectations might differ in different countries' schools. Like you said, their expectations are very high there [in other countries], but you come here [to the U.S.] and it's different, it's lower, and so they definitely feel a lot dumber than how they were back where they were [in their native country]. Xuan: I actually have this [poem] marked, too. A lot of my students are EL, and I have some of my students come up to me saying, "I try so hard! I study every night when I come home. 
In my country this [biology] was easy to me...” But I think walking through it with them, reassuring them that you do understand their situation and they can do this...

Ali: I thought that it [the poem] spoke to the power of the language in the classroom. The language is really the gatekeeper as to if the child is going to succeed. And because the child is still smart, it's just that they weren't able to articulate their answers or understandings in the language that was being presented in the classroom. So if they were able to, perhaps, perform in their native language, then you would see that there wasn't any difference [with mainstream students]. And I think that classroom teachers and schools have to really rethink that and look at that as we move forward with English language learners.

In addition to merging the discourse signaling the use of windows (i.e., third-person) and mirrors (i.e., first-person), participants connect the two to share and discuss their classroom practice with ELs. In a class with 1 pre-service secondary teacher, 4 in-service teachers (i.e., 1 early childhood, 1 elementary, 2 secondary), and 1 elementary principal in highly diverse neighborhoods in Chicago, as well as five of the six participants growing up in immigrant families from Mexico, Serbia, Vietnam, and the Philippines, Jorge's perspectives allowed for both windows and mirrors, but pushed them beyond to open sliding glass doors to connect and represent professional practice with ELs.

\section{Instructional Logistics to Support Teacher Learning}

In addition to texts serving as tools to mediate representations of practice in literature discussions, data also demonstrated orientations to practice and norms of interaction that opened or closed opportunities for learning (Little, 2002). I found specific instructional and logistical factors that impacted collaborative discourse in literature circles: (a) implementation of literature discussion strategies and (b) strategic grouping of participants. In each sub-section, I explicate the thematic finding and provide examples from literature discussions. 
Implementation of literature discussion strategies. The selection and use of specific organizational and reader response strategies proved central to mediate teachers' dialog and learning. Organizational strategies provided structures for participants to engage in literature discussions, such as the use of roles (Barone \& Barone, 2012; Peterson \& Belizaire, 2006) to outline specific purpose for reading and dialoging (e.g., discussion director, vocabulary enricher). Reader response strategies offered direction to support meaning making, such as the graffiti board approach (Short, 1997) for group members to visually and graphically brainstorm ideas from the text to discuss.

In fall 2010, candidates dialoged around various texts related to the role of culture in learning in a foundational course. Having just initiated literature circles, I did not have structures in place for participants to incorporate strategies. When groups discussed texts without formal structure or organization, conversations remained at surface-level as participants shared statements with sentence frames like "I liked the part when" and "I thought it was funny when." In a dialog about The Name Jar (Choi, 2001), the story of a Korean immigrant who struggles in an American classroom, candidates did not push beyond surface-level observations. After exhausting details with statements such as "I think that would be cool if we had stamps with our names on it" and "I thought the teacher was cute," Andrea opened an opportunity to explore the role of culture in learning. Andrea: Something that stood out to me in the book was when the mom was like, "Make sure you learn English to be a good Korean girl.”

Carmen: Yeah, like her expectations.

Kara: That was kind of weird.

Mandy: Yeah, be a good student, be a good Korean.

Carmen: Behave nicely.

Andrea: Like, she [her mom] was concerned more with the appearances of being Korean, more so than how she [main character] was doing in school or how she was adjusting. 
Andrea shared an observation about the mother's cultural and linguistic expectations; however, without the structure of a reader response strategy to support meaning making at a deeper level, the opportunity to mediate dialog closed. Instead, the conversation returned to surface-level observations related to what they liked about the text.

Two years later in fall 2012, six teachers dialoged using My Diary from Here to There (Perez, 2009), where a young girl and her family leave Mexico and cross the border to California. Using the provided list of reader response strategies and literature circle procedures, participants agreed to use a variation of the timeline strategy, organizing major events as connected to the main character's feelings, thoughts, and tensions (Short, 1997). They paged through the text to first highlight the events and then discuss her corresponding feelings, which mediated an overall dialog around the sociocultural facets impacting this character.

Amanda: This is where she's [Amada, main character] worried she won't be able to speak Spanish. She's [worried that she's] going to lose it [Spanish] and never learn English.

Cindy: She's kind of bothered by her brothers. And she's kind of annoyed, how they [her brothers] are not upset. I mean, she's alone.

Kate: And she's outnumbered, with all of the brothers, and then there's just her. She needs to kind of go along with what's happening without having any of that support.

Ronda: I mean, even the parents too I think, they [the mom and dad] are just talking about the opportunities that will be there in this new place [the U.S.].

Heather: I feel like she's also still feeling unsettled, the last question: Will we ever go back [to Mexico]? So it's not even clear that they [the family] have a home [in California]. Evan: Might want to add under that, that they [the parents] had to sell everything... Obviously [the plot] is supposed to give you an indication of their socio-economic reality, borrowing a car, everything they have, they sell. 
The participants continued to dialog about circumstances of immigration, border crossing, and family situations impacting young Amada, the main character who could have been a student in their diverse suburban classrooms. Through use of the timeline strategy, teachers reviewed the text pageby-page, organized events and feelings, and discussed realities that impact immigrant students, including social, emotional, familial, cultural, and linguistic facets. Since small groups selected different texts related to borders and immigration for this class session, the resulting poster then mediated whole group dialog as groups shared learning with others.

As an added layer of structure to organize participants' reading and meaning making prior to literature circles, I asked small groups to select a procedure or strategy in the prior class session when possible. One small group of graduate students - one in-service teacher, one in-service principal, and one pre-service teacher - chose to utilize the Clone the Author strategy (Short, 1997) to discuss Friends from the Other Side (Anzaldúa, 1997), a story about friendship between legal and illegal immigrant children on the Texas-Mexico border. The strategy asked readers to independently write important points on individual cards while reading to organize the literature discussion.

Arturo: I put nine different like words on cards as soon as I finished reading the book. Just as soon as they came to mind, like important things. So my words were friendship, alienation, immigration which, and then I'll give more details so we can talk about it: socio-economic differences, courage - as in the girl extending out to the other friend, healing powers, wisdom of elders, and growing up and coming of age.

Ali: I put paying attention to another's needs, understanding immigration, and crossing the border... I put bravery because she [Prietita, main character], they were all very brave, everyone. I put that we're different yet there's some [things that make us] the same. Kindness, the actions of Prietita and the herb woman, the religious beliefs and symbols throughout the whole book. When you want something that you kind of fight for it. 
With note cards set on the table, participants organized ideas by theme and engaged in deep dialog about book events, tackling issues such as illegal immigration and prejudice and discrimination within and among immigrants. With Arturo and Diana as second-generation Mexican immigrants and Ali the principal in a predominantly Mexican immigrant community, the reader response strategy opened the opportunity for participants to organize deep-level ideas and connections before the discussion, moving beyond surface-level observations of what they liked or disliked in the text.

Strategic grouping of participants. Participant grouping impacted norms of interaction (Little, 2002) in literature circles. Two particular traits of participants supported mediation of discussions: (a) those with prior experiences related to those in the children's texts, typically those who learned English as a second language or immigrated to the U.S., and (b) those with prior knowledge of classroom practice with diverse learners, particularly those later in teacher preparation programs who had spent extensive time in urban classrooms. Nevertheless, since all participants brought a rich array of background knowledge and experiences to literature discussions, I found no prescriptions to approach the clustering of teachers and candidates. As data from different semesters demonstrated, depth of dialog depended on individuals' connections to texts and how those connections then mediated collaborative dialog and meaning making.

With discussions mediated by texts about culturally and linguistically diverse children, participants with diverse backgrounds, knowledge, and experiences supported meaning making in small groups. Having grown up in households with cultural traditions and native languages, or having lived in other countries, participants drew from background knowledge and experiences to mediate dialog in literature circles. In a discussion among graduate students in spring 2012 using vignettes from Family Pictures (Garza, 1990), two Caucasian females and one Latina female used a dynamic interchange of windows and mirrors to support one another's meaning making. 
Samantha: I don't have a profound knowledge of Mexican culture and I'm trying to look at it [the text] from a perspective from an outsider's perspective and what is it that makes this [book] truly Mexican? I love here seeing the part with the healer and there is a picture of the Virgin of Guadalupe, and those are things that I very much identify with the Mexican culture that makes it just scream Mexican and not Costa Rican, not Guatemalan. And I don't know if you [to Alma] have any things in particular to add to that but the Catholicism or the cross that is there and also I noticed, I think it was the tamale making, as well.

Mindy: The Last Supper?

Samantha: Yeah, the Last Supper! Because that's actually something even in Costa Rica every family household has a picture, but I would say that I don't know if that is something truly Mexican or you know that crosses many Latin [American] culture's borders. But that is something that I have seen in many homes in my travels through Latin America so. Alma: It's so great that you pointed that out because I think that is a kitchen scene, that is just where so much happens and lets you know families in my Nana's house like it relates to how colorful the kitchen was not just how colorful, but everyone had colorful clothes on and the walls were a color and all of these things and certainly the depiction of The Last Supper. I know at my Nana's house, there are all sorts of religious portraits on the walls. Samantha, a Caucasian female with extensive experiences in Latin America, utilized norms of interaction to position herself as an outsider and use the text as a window to make meaning of the Mexican culture as portrayed in the vignette. Alma, a third generation Mexican American from Arizona, supported Samantha's meaning making with her insider knowledge and use of the same vignette as a mirror. 
When the dialog focused on a second vignette, Samantha shifted in the interaction to utilize her experiences in Costa Rica to contribute to co-construction of knowledge with personal reflections related to borders and border crossings.

Samantha: I actually too just the whole connection with nature which really distinguishes this family as that okay I mean she crosses the border she has got a family right in the U.S then she goes across the border to see her family in Mexico, but what is common is that their nature seems to be in both places and they are both relatively rural settings. I mean, when I lived in Costa Rica, I had to kill chickens (laughter), which is a very non-academic experience. When you think about seeing a kid that is in this [rural Latin American] environment and then this [killing chickens] is what they can identify with and they walk into a [mainstream American] classroom, it could be very intimidating because I know for me when I walk into an academic classroom centered around Spanish it is very intimidating because that wasn't the kind of Spanish that I learned, I learned this [non-academic Spanish]. Mindy: So one thing real quick, about the border crossing [vignette] that I found really interesting is when they are kicking the cactus (refers to painting in text), you can see that there is like the barbed wire broken down. So you are like crossing a border to get there, and I don't necessarily know if that is how they [the characters] get in and out of the little cactus area, but I just think it is very interesting because that is the kind of Mexican American culture is there is so much border crossing like if you go and visit family in Mexico or even within your own lives you constantly cross borders.

Alma: That's a really great point. I didn't even think about that.

Whereas Samantha utilized discourse that positioned her as the outsider and Alma as the insider in the first exchange, Samantha drew upon experiences in the Peace Corps in Costa Rica to explain nuances in ELs' linguistic background knowledge. Mindy, a Caucasian female from the Midwest, 
built on the mention of border-crossing with an observation from the canvas painting and corresponding vignette. Mindy, who sought out universal themes early in the interaction, used the text as a window to make a culturally specific statement about individuals crossing metaphorical borders. Varying background knowledge and experiences led to an interchange of windows and mirrors, revealed by insider and outsider discourse, which in turn mediated collaborative dialog. Whereas diverse cultural and linguistic backgrounds impacted the norms of interaction in literature discussions, participants' prior knowledge and experiences from classroom practice and university coursework also supported critical dialog on ELs. When participants had extensive experience in classrooms and related knowledge from other university courses, literature discussions explicitly linked culturally relevant texts with professional knowledge and practice. In spring 2011, three Caucasian, pre-service teachers engaged in dialog around Grandma and Me at the Flea (Herrera, 2002) and Shota and the Star Quilt (Bateson-Hill, 2001).

Jenny: What is standing out to me between the two books is how it shows that the collectivist nature of Latino and Native American cultures, that people work together and you spend a lot of time with your extended family. I think a lot of times in education the dominant culture promotes competitiveness and [for] a lot of students it conflicts with their home environments and what values they grew up with. So kind of learning about their cultures and kind of fostering that in the classroom, I think that would be really helpful. Leanne: That's a great point and I know that goes back to the whole funds of knowledge thing, like getting to know the families ... they are going through so many things already identity-wise, that would maybe mean [teachers] fostering more group projects or group work, bouncing ideas off each other and making that [collaboration] a priority, which would not only be beneficial to these different cultures, but to kids in general. Just to teach them that teamwork is a good thing. You don't have to be on a team by yourself. 
Matt: Even reading a book about it [cultural and linguistic diversity] like one of these would be huge. Just because you're taking class time out and be highlighting or integrating curriculum, like social studies because that is all I know. Just like different ways through history that people work together instead of the American myth of, "The president did it, or the leader, the white male is doing it." So seeing these ideas by people who weren't just another white person, I think is big. I did a lesson yesterday, and it wasn't with EL students, but it was doing these different documents and analyzing by the students. And so it just said "author" but it didn't have like ethnicity, race, or anything like that. And so they were like, "Just another white dude.” And I was like, “Actually, this time it isn't." Leanne: It's really interesting that you would pick up on that [students' assumption of race]. Matt: Because that's the way we teach history. That's how we teach education. It's just tough. Jenny: People [white men] that the history focuses on a lot of the time.

Leanne: It's so important to give other viewpoints. We were talking about this in [another] class on reading in children's books like Anne Frank's Diary. What were kids in the U.S. feeling at that time and how are their feelings different? So it is amazing to see the different perspectives and the different authors that are writing and how that can affect the book itself. So that was really interesting. Jenny: Yeah, and especially in history and literature, reading from different perspectives and learning history from all different places and seeing people who like, seeing people of color in role model roles. It's somebody [a historical persona] to look up to other than a white, protestant male. I think that is really, really important.

In this literature discussion, which group members deemed the "most intense lit[erature] session ever," candidates' background knowledge from coursework and fieldwork in urban schools mediated dialog and opened opportunities for learning about ELs. Whereas the two texts portraying 
a Mexican American boy and Native American girl provided windows to initiate the conversation, participants used deeper themes and ideas as sliding glass doors to engage in critical discussion about race, culture, and language in classrooms and schools.

\section{Discussion}

As teacher educators attempt to prepare teachers for the growing linguistic diversity in U.S. schools (Shin \& Kominski, 2010; USDOE, 2010), culturally relevant literature circles provide collaborative locales for current and future teachers to co-construct knowledge about the unique and diverse nature of ELs in classrooms. In this paper, I share findings of an investigation with teachers and candidates spanning five academic semesters centered on the following research questions: (a) How does participation in culturally relevant literature circles support teachers' and teacher candidates' dialog about ELs? (b) What factors open or close opportunities for learning in culturally relevant literature circles with teachers and teacher candidates? First, results demonstrate that stories written by and for diverse individuals, specifically those portraying the nuanced lived realities of culturally and linguistically diverse children and families, allow participants to explore the unique and complex facets of ELs through windows, mirrors, and sliding glass doors (Bishop, 1990). Second, findings indicate that culturally relevant literature circles have the potential to mediate deep and meaningful dialog about ELs, but specific logistical actions open and close considerations of practice and opportunities for learning (Little, 2002), such as incorporating strategies and grouping participants. In this section, I close with discussion of and conclusions on findings related to each research question, followed by discussing study limitations that serve to inform future research.

Findings from the first research question reveal that culturally relevant picture books provide opportunities for teachers and candidates to dialog and learn about ELs. Whereas past research indicates the efficacy of children's and adolescent literature to impact candidates' perceptions of cultural diversity (Florio-Ruane, 2001; Labbo, 2007; Lohfink \& Curtis, 2011; Nathenson-Mejia \& 
Escamilla, 2003), results from this study demonstrate how texts serve as windows, mirrors, and sliding glass doors (Bishop, 1990) for exploration of the lives and realities of linguistically diverse children and families. In addition to the theme of immigration (Gregor \& Green, 2011), literature circle participants collaboratively explored themes and ideas specific to linguistically diverse students, such as (a) students' social and emotional uncertainties about learning and not learning English when starting in U.S. schools, as reflected in teachers' dialog about Amada (Pérez, 2009), (b) students' and families' social and emotional circumstances related to immigration, such as discrimination and extended time away from families and friends, as represented in various texts (Anzaldua, 1997; Medina, 2001; Pérez, 2009), (c) students' and families' negotiation of cultural differences between schools in their native countries and in the U.S., as exhibited in discourse about Jorge (Medina, 2001), (d) students' complex roles as translators and language brokers and the corresponding benefits and demands, emergent from the conversation about Shota (Bateson-Hill, 2001), and (e) teachers' deficit-based perspectives that can pervade expectations of ELs, as well as the importance of native language support and assessment in academic instruction, exhibited in responses to culturally relevant poetry (Medina, 2001). By utilizing texts that highlight the perspective of the linguistically diverse child, teachers explore the social, emotional, cultural, and linguistic dimensions of children and families (Heineke et al., 2012; Wrigley, 2000) that get overshadowed in the staunch focus on academics in contemporary educational settings (Herrera, 2010).

Results from the first research question hold significance for teacher education for ELs. To positively impact student achievement in today's classrooms, teachers and candidates require specific knowledge, skills, and dispositions for ELs, including exploration of the rich assets, dimensions, and stories that each individual child brings into the classroom (Herrera, 2010). An active and innovative approach to teacher education for ELs, culturally relevant literature circles allow teachers and candidates to co-construct knowledge on big ideas about language that scholars outline as pertinent 
to effective teacher practice (Valdés et al., 2005), as well as social justice issues impacting ELs such as borders and immigration (Bartolomé \& Balderrama, 2001) and linguistically responsive pedagogical practices such as native language instruction and assessment (Lucas et al., 2008). Additionally, through these nuanced stories and discussions about individual children and families, teachers deconstruct the homogenous label of EL that typically usurps a richly diverse population of students in U.S. classrooms and schools (González et al., 2005; Gutiérrez \& Orellana, 2006; Gutiérrez \& Rogoff, 2003) and often leads teachers to unknowingly espouse the deficit perspective about the "problems" that ELs bring to the classroom (Gutiérrez \& Orellana, 2006, p. 502). In this way, the incorporation of culturally relevant literature circles in teacher education allows participants to begin to move beyond standardized labels and generic instructional strategies for ELs typical in most university courses and textbooks (Echevarria, Short, \& Vogt, 2011).

Building on the first finding related to the efficacy of culturally relevant literature circles, results from the second research question indicate the necessary logistical and instructional factors to support teacher dialog and learning within this pedagogical approach. Findings from extant research with children emphasize the value of using culturally relevant texts in literature circles to mediate critical discussions (Martínez-Roldán \& Malavé, 2004; Medina \& Martínez-Roldán, 2011). Additionally, previous studies with children and adolescents demonstrate the need for explicit structures to support students' literature circles, specifically reader response strategies such as roles (Barone \& Barone, 2012; Peterson \& Belizaire, 2006). Interestingly, despite the theoretical differences in child and adult learners described by the learning theories of pedagogy and andragogy, respectively (Merriam, 2001), my findings extend similar recommendations for literature circles with children and adolescents to those conducted with adults. As demonstrated in the logistical and instructional factors that opened and closed opportunities for learning and considerations of practice (Little, 2002), adults require purpose, structure, and peers to collaboratively engage with texts written 
for children. In this way, adults need access and introduction to literature circle strategies and procedures (Short, 1997) to engage in productive dialog among diverse participants with various sources of background knowledge related to texts (Martínez-Roldán \& Heineke, 2011).

Findings from the second research question reveal important considerations for teacher educators who attempt to engage teachers and candidates in collaborative learning settings, such as literature circles. This study confirms extant educational research that demonstrates the efficacy of social interaction in teacher learning communities (Cochran-Smith \& Lytle, 1998; Grossman et al., 2001; Little, 2002), including the specific constructs of book clubs and literature discussions with chapter books (Martínez-Roldán \& Heineke, 2011; Florio-Ruane, 2001; Monroe-Baillargeon \& Shema, 2010); however, the significance of this study is the specificity in how this learning occurs. Whereas community of practice literature is often ambiguous about how community practice becomes known and shared (Fuller, 2007; Little, 2002), my results pinpoint the specific ways in which participants co-construct knowledge and collaboratively consider practice with ELs. As demonstrated by using discourse analysis as an analytic tool (Gee, 2005; Little, 2002), opportunities for learning open through the mediation of textual artifacts, structures and strategies, and group members' background knowledge and experiences. Through this approach to teacher education for ELs, specifically engaging adult participants in active, interactive, and structured dialog mediated by picture books and reader response strategies, teachers and candidates co-construct knowledge for classroom practice with diverse students (Cochran-Smith \& Lytle, 1998).

Whereas the results of this study demonstrate the efficacy of culturally relevant literature circles for EL teacher preparation, study limitations provoke considerations for future analyses and research. First, the findings presented in this paper, with a breadth of data from 23 literature circles across five semesters, are limited in depth, due to the broad approach and objective to share overarching themes and trends across discussions. Within this larger pool of data, subsequent data 
analyses require exploration of discrete literature discussions to capture individuals' identity development, nuanced experiences, and learning (Engeström, 2007). Additionally, forthcoming analyses should seek to merge Little's three-facet conceptual scheme into the summative trajectory of development (2002) to investigate how teachers' and candidates' talk changes over time through ongoing development of and changing participation in communities of practice (Little, 2002). Second, in addition to the limitations of the wide-lensed analysis presented in this particular paper, future research into culturally relevant literature circles should deliberate on the positionality that limited this study's design. Specifically, despite the strategies incorporated to enhance validity, future research should eliminate the dual role of course instructor and researcher. Finally, and ultimately most important to the research questions on teacher preparation for linguistically diverse students, to contribute to the central matter of improving the teaching corps to impact EL student development and achievement (Gándara \& Maxwell-Jolly, 2006), research on culturally relevant literature circles must investigate impact on teaching and learning with ELs in classroom practice. 


\section{References}

Ann, J., \& Peng, L. (2005). The relevance of linguistic analysis to the role of teachers as decision makers. In K. E. Denham \& A. C. Lobeck (Eds.), Language in the schools: Integrating linguistic knowledge into K-12 teaching (pp. 71-86). London: Routledge.

Anzaldua, G. (1997). Friends from the other side / Amigos del otro lado. San Francisco, CA: Children's Book Press.

Barone, D., \& Barone, R. (2012). Building background knowledge with literature circles. Voices from the Middle, 20(1), 10-15.

Bartolomé, L. I., \& Balderrama, M. V. (2001). The need for educators with political and ideological clarity: Providing our children with "the best." In M. L. Reyes \& J. Halcón (Eds.), The best for our children: Critical perspectives on literacy for Latino students (pp. 48-64). New York: Teachers College Press.

Bateson-Hill, M. (2001). Shota and the star quilt. Little Rock, AR: Zero to Ten.

Birchak, B., Connor, C., Crawford, K. M., Kahn, L. H., Kaser, S., Turner, S., et al. (1998). Teacher study groups: Building community through dialogue and reflection. Urbana, IL: National Council of Teachers of English.

Bishop, R. S. (1990). Mirrors, windows, and sliding glass doors. Perspectives, 6 (3), ix-xi.

Bunting, E. (1998). Going home. New York: Harper Collins.

Choi, Y. (2001). The name jar. New York: Knopf.

Clair, N. (1998). Teacher study groups: Persistent questions in a promising approach. TESOL Quarterly, 32, 465-492.

Cochran-Smith, M., \& Lytle, S. L. (1998). Relationships of knowledge and practice: Teacher learning in communities. Review of Research in Education, 24, 249-305.

Cohen, B. C., \& Clewell, B. C. (2007). Putting English language learners on the educational map. Education in Focus: Urban Institute Policy Brief. Retrieved on December 27, 2012, from http://www.urban.org/UploadedPDF/311468_ell.pdf

Commins, N. L., \& Miramontes, O. B. (2006). Addressing linguistic diversity from the outset. Journal of Teacher Education, 57, 240-246.

Echevarria, J., Short, K., \& Vogt, S. (2011). Making content comprehensible for English learners: The SIOP model. Boston, MA: Allyn \& Bacon.

Engeström, Y. (2007). From communities of practice to mycorrhizae. In J. Hughes, N. Jewson, \& L. Unwin (Eds.), Communities of practice: Critical perspectives (pp. 41-54). New York: Routledge.

Erickson, F. (1986). Qualitative methods in research on teaching. In M. Wittrock (Ed.). The handbook of research on teaching, 3rd ed. (pp. 119-162). New York: Macmillan.

Florio-Ruane, S. (2001). Teacher education and the cultural imagination. Mahwah, NJ: Lawrence Erlbaum. 
Fredericks, L. (2012). The benefits and challenges of culturally responsive EFL critical literature circles. Journal of Adolescent \& Adult Literacy, 55(6), 494-504.

Fuller, A. (2007). Critiquing theories of learning and communities of practice. In J. Hughes, N. Jewson, \& L. Unwin (Eds.), Communities of practice: Critical perspectives (pp. 17-29). New York: Routledge.

Gándara, P., \& Hopkins, M. (2010). The changing linguistic landscape of the United States. In P. Gándara \& M. Hopkins (Eds.), Forbidden language: English learners and restrictive language policies (pp. 7-19). New York: Teachers College.

Gándara, P., \& Maxwell-Jolly, J. (2006). Critical issues in developing the teacher corps for English learners. In K. Téllez \& H.C. Waxman (Eds.), Preparing quality educators for English language learners: Research, policies, and practices (pp. 99-120). Mahwah, NJ: Lawrence Erlbaum.

Garza, C. L. (2000). In my family. San Francisco, CA: Children's Book Press.

Garza, C. L. (1990). Family pictures. San Francisco, CA: Children’s Book Press.

Gee, J. P. (2005). Introduction to discourse analysis: Theory and method. London: Routledge.

González, N., Moll, L. C., \& Amanti, C. (2005). Funds of knowledge: Theorizing practices in households and classroom. Mahwah, NJ: Lawrence Erlbaum.

Gregor, M. N., \& Green, C. (2011). Welcoming the world's children: Building teachers' understanding of immigration through writing and children's literature. Childhood Education, $87,421-429$.

Grossman, P., Wineburg, S., \& Woolworth, S. (2001). Toward a theory of teacher community. Teachers College Record, 103, 942-1012.

Gutiérrez, K. D., \& Orellana, M. F. (2006). The "problem” of English learners: Constructing genres of difference. Research in the Teaching of English, 40, 502-507.

Gutiérrez, K. \& Rogoff, B. (2003). Cultural ways of learning: Individual traits or repertoires of practice. Educational Researcher, 32 (5), 19-25.

Heineke, A. J., Coleman, E., Ferrell, E., \& Kersemeier, C. (2012). Opening doors for bilingual students: Recommendations for building linguistically responsive schools. Improving Schools, 15, 130-147.

Herrera, J. F. (2002). Grandma and me at the flea. San Francisco, CA: Children's Book Press.

Herrera, S. (2010). Biography-driven culturally responsive teaching. New York: Teachers College Press.

Jiménez, F. (2000). La mariposa. St. Louis, MO: Turtleback.

Kozulin, A. (1996). A literary model for psychology. In D. Hicks (Ed.), Discourse, learning, and schooling (pp. 145-164). New York: Cambridge University Press. 
Labbo, L. D. (2007). The golden rule should rule: Modes revelations on pre-service teachers' explorations into cultural identity, prejudice, and empathy. Journal of Reading Education, 33(1), 40-44.

Lachtman, G. D. (1995). Pepita talks twice. Houston, TX: Arte Publico Press.

Latendresse, C. (2004). Literature circles: meeting readings standards, making personal connections, and appreciating other interpretations. Middle School Journal, 35(3), 13-20.

Levine, E. (1995). I hate English. New York: Scholastic.

Little, J. W. (2002). Locating learning in teachers' communities of practice: Opening up problems of analysis in records of everyday work. Teaching and Teacher Education, 18, 917-946.

Lohfink, G., \& Curtis, L. J. (2011). Facilitating pre-service teachers' cultural responsiveness through multicultural children's literature. The Journal of Multiculturalism in Education, 7, 1-21.

Lucas, T., Villegas, A. M., \& Freedson-González, M. (2008). Linguistically responsive teacher education: Preparing classroom teachers to teach English language learners. Journal of Teacher Education, 59, 361-373.

McLaughlin, M., \& Talbert, J. E. (2006). Building school-based teacher learning communities: Professional strategies to improve student achievement. New York: Teachers College Press.

Martínez-Roldán, C., \& Heineke, A. J. (2011). Latino literature mediating teacher learning. Journal of Latinos and Education, 10, 245-260.

Martínez-Roldán, C., \& Malavé, G. (2004). Language ideologies mediating literacy and identity in bilingual contexts. Journal of Early Childhood Literacy, 4, 155-180.

McElvain, C. M. (2010). Transactional literature circles and the reading comprehension nof English learners in the mainstream classroom. Journal of Research in Reading, 33(2), 178-205.

Medina, C. L., \& Martínez-Roldán, C. (2011). Culturally relevant literature pedagogies: Latino students reading in the borderlands. In J. C. Naidoo (Ed.), Celebrating cuentos: Promoting Latino children's literature and literacy in classrooms and libraries (pp. 259-272). Santa Barbara, CA: ABCCLIO.

Medina, J. (1999). My name is Jorge on both sides of the river. Honesdale, PA: Wordsong.

Merriam, S. B. (2001). Andragogy and self-directed learning: Pillars of adult learning theory. New Direction for Adult Continuing Education, 89, 3-14.

Monroe-Baillargeon, A., \& Shema, A. L. (2010). Time to talk: An urban school's use of literature circles to create a professional learning community. Education and Urban Society, 42, 651-673.

Musanti, S. I., \& Pence, L. (2010). Collaboration and teacher development: Unpacking resistance, constructing knowledge, and navigating identities. Teacher Education Quarterly, 37, 73-89.

Nathenson-Mejia, S., \& Escamilla, K. (2003). Connecting with Latino children: Bridging cultural gaps with children literature. Bilingual Research Journal, 27, 101-116. 
Pérez, A. I. (2009). My diary from here to there. New York: Lee \& Low.

Peterson, S., \& Belizaire, M. (2006). Another look at roles in literature circles. Middle School Journal, 37(4), 37-43.

Rodgers, R., \& Mosely, M. (2008). A critical discourse analysis of racial literacy in teacher education. Linguistics and Education, 19, 107-131.

Rodriguez, L. (1998). América is her name. Seattle, WA: Curbstone.

Rogoff, B. (2003). The cultural nature of human development. New York: Oxford University Press.

Rogoff, B. (1994). Developing understanding of the idea of communities of learners. Mind, Culture, and Activity, 1, 209-229.

Ruiz, J. H., \& Koch, C. A. (2010). Bilingual education programs and English language learners in Illinois. Springfield, IL: Illinois State Board of Education.

Shelton-Strong, S. J. (2012). Literature circles in ELT. ELT Journal, 66(2), 214-223.

Shin, H. B., \& Kominski, R. A. (2010). Language Use in the United States: 2007, American Community Survey Reports, ACS-12. U.S. Census Bureau, Washington, DC.

Short, K. G. (1997). Literature as a way of knowing. York, ME: Stenhouse.

Thein, A. H., Guise, M., \& Sloan, D. L. (2011). Problematizing literature circles as forums for discussion of multicultural and political texts. Journal of Adolescent \& Adult Literacy, 55(1), 15 24.

U.S. Department of Education, National Center for Education Statistics (2010). The condition of education 2010 (NCES 2010-028).

Valdés, G., Bunch, G., Snow, C., Lee, C., \& Matos, L. (2005). Enhancing the development of students' language. In L. Darling-Hammond \& J. Bransford (Eds.), Preparing teachers for a changing world: What teachers should learn and be able to do (pp. 126-168). San Francisco, CA: Jossey-Bass.

Vygotsky, L. S. (1978). Mind in society: The development of higher psychological processes. (M. Cole, V. JohnSteiner, S. Scribner, \& E. Souberman, Eds). Cambridge, MA: Harvard University Press.

Wenger, E. (1998). Communities of practice: Learning as a social system. Systems Thinker. Retrieved September 10, 2006, from http://www.co-i-l.com/coil/knowledge-garden/cop/lss.shtml

Wood, K., Roser, N., \& Martínez, M. (2001). Collaborative literacy: Lessons learned from literature. The Reading Teacher, 55, 102-111.

Wrigley, T. (2000). The power to learn: Stories of success in the education of Asian and other bilingual pupils. Staffordshire, England: Trentham Books Limited. 